\title{
Immunoreactive beta-melanocyte-stimulating hormone in cerebrospinal fluid and plasma in hypopituitarism : evidence for an extrapituitary origin
}

\author{
SAM SHUSTER, ANDREW SMITH, NORMAN PLUMMER, ANTHONY THODY, \\ FREDERICK CLARK
}

British Medical fournal, 1977, 1, 1318-1319

\section{Summary}

Immunoreactive beta-melanocyte-stimulating hormone (beta-MSH) was measured in the plasma of 19 patients with hypopituitarism and in the cerebrospinal fluid (CSF) of five of these patients. In neither plasma nor CSF were the beta-MSH concentrations significantly different from those in normal controls. These observations raise the possibility that beta-MSH may be produced by and secreted from neural tissue; this is supported by the finding of beta-MSH in high concentrations in many parts of the brain.

\section{Introduction}

We have recently described the presence of immunoreactive $\beta$-melanocyte-stimulating hormone $(\beta-\mathrm{MSH})$ in $\mathrm{CSF},{ }^{1}$ where, unlike other pituitary hormones, ${ }^{2}$ its concentration is greater than that in the plasma. We therefore suggested that immunoreactive $\beta$-MSH might have a physiological role in the central nervous system in man. ${ }^{1}$ If this were so it would be important to find out what happens to $\beta$-MSH concentrations in the cerebrospinal fluid (CSF) when plasma levels are either raised or depressed. In an attempt to answer this last question we studied CSF and plasma $\beta-\mathrm{MSH}$ concentrations in patients with hypopituitarism.

\section{Patients and methods}

In five patients with severe panhypopituitarism CSF was obtained as part of their clinical investigation by lumbar puncture and plasma by venepuncture. Hypopituitarism followed craniotomy in four patients; and a chromophobe adenoma was removed in three of these patients and a craniopharyngioma in one. The fifth patient had idiopathic panhypopituitarism. All required replacement treatment with hydrocortisone and thyroxine. The one man was also given testosterone. Immunoreactive $\beta-\mathrm{MSH}$ was measured by a modification of the method of Thody and Plummer. ${ }^{3}$ Plasma $\beta-\mathrm{MSH}$ had previously been measured, using Thody and Plummer's method, ${ }^{3}$ in another 14 patients with hypopituitarism. These patients had varying degrees of hypopituitarism and were receiving replacement treatment with hydrocortisone, thyroxine, and testosterone as indicated.

\footnotetext{
University Department of Dermatology, Royal Victoria Infirmary, Newcastle upon Tyne NE1 4LP

SAM SHUSTER, PHD, FRCP, professor

ANDREW SMITH, MB, MRCP, Wellcome research fellow

NORMAN PLUMMER, PHD, research associate

ANTHONY THODY, PHD, lecturer

Newcastle General Hospital, Newcastle upon Tyne NE4 6BE FREDERICK CLARK, FRCP, consultant physician
}

\section{Results}

In the five patients in whom both plasma and CSF were studied CSF $\beta$-MSH concentrations were higher than those found previously, ${ }^{1}$ but they were not significantly higher (mean $\pm S E$ of mean $78 \cdot 8 \pm 15 \cdot 8 \mathrm{ng} / \mathrm{l}$ in this study compared with $\left.60 \cdot 1 \pm 8 \cdot 9 \mathrm{ng} / \mathbf{l}^{1}\right)$. Furthermore, the plasma concentrations in these five patients were higher than those in normal controls, but again the difference was not significant $(23 \cdot 6 \pm 5 \cdot 6 \mathrm{ng} / \mathrm{l}$ compared with $16 \cdot 2 \pm 1 \cdot 2 \mathrm{ng} / \mathrm{l})$ (fig 1).

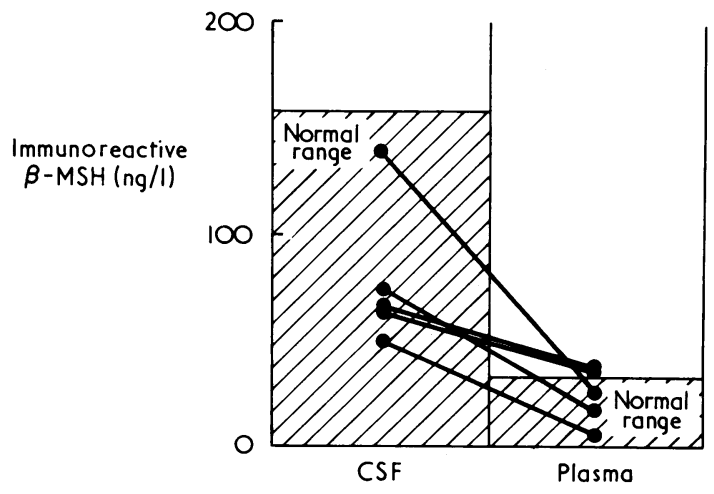

FIG 1-Normal plasma and CSF concentrations of immunoreactive $\beta-M S H$ in five patients with severe hypopituitarism.

When plasma $\beta$-MSH levels from all 19 patients were compared with normal levels there was no significant difference (fig 2), the overall mean plasma concentration being $94 \cdot 0 \pm 21.3 \%$ of normal.

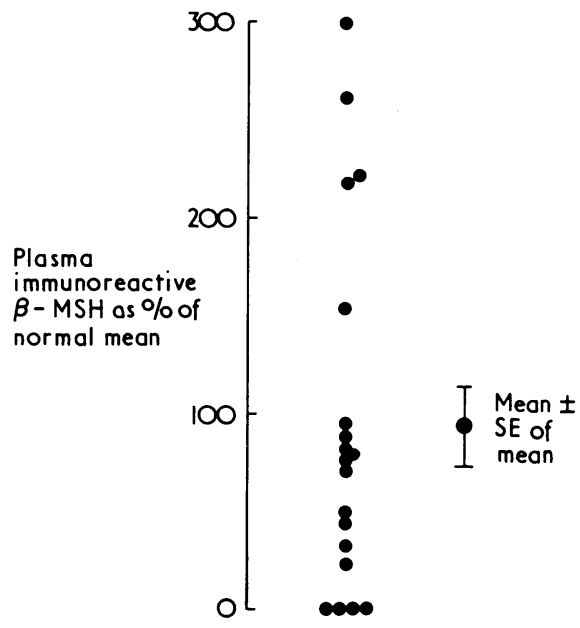

FIG 2-Plasma immunoreactive $\beta$-MSH concentrations in patients with hypopituitarism expressed as a \% of normal mean. The mean value does not differ significantly from normal. 


\section{Discussion}

These findings show that in patients with hypopituitarism both CSF and plasma $\beta-\mathrm{MSH}$ concentrations are maintained within the normal range, the CSF:plasma ratio remaining normal at about 3:1. Gonadotrophin and growth hormone secretion decline early in hypopituitarism; ACTH secretion declines later on ${ }^{4}$ and would be expected to be well below normal in our patients with severe hypopituitarism. ${ }^{5}$ Thus there seems to be a dissociation between the secretion of $\beta-\mathrm{MSH}$ and the secretion ACTH in hypopituitarism.

The source of the $\beta-M S H$ is unlikely to have been the pituitary because some of the patients had severe panhypopituitarism while others had had a surgical hypophysectomy. Residual pituitary tissue would in any case be an unlikely explanation of the findings because there seems to be no direct route for pituitary hormones into CSF other than through the blood. Thus the CSF concentration of most pituitary hormones increases above their plasma concentration only when there is suprasellar extension of a pituitary tumour, ${ }^{2}$ and preliminary studies (unpublished) have shown that even when plasma $\beta-\mathrm{MSH}$ concentrations are grossly raised the CSF concentration remains normal. Thus it is unlikely that CSF $\beta-M S H$ concentrations are maintained by pituitary secretion into the blood.

An attractive explanation of our findings is that $\beta-\mathrm{MSH}$ is produced by and secreted from nervous tissue. To test this we have looked for and found considerable amounts of immunoreactive $\beta-\mathrm{MSH}$ in various regions of the brain; we also found comparable amounts of biologically active $\mathrm{MSH}^{6}{ }^{6}$ which suggests that the immunoreactive $\beta-\mathrm{MSH}$ found was not due to non-specific activity. It therefore seems likely that the high concentrations of $\beta-\mathrm{MSH}$ in CSF arise from direct secretion by neural tissue and it will be interesting to see whether high concentrations of other neuropeptides? are also found in the CSF. Further studies are required to confirm that the brain can indeed maintain normal plasma $\beta-\mathrm{MSH}$ levels after complete surgical hypophysectomy because this suggests that the turnover of brain $\beta-M S H$ is much faster than in the normal pituitary, since total brain $\beta-\mathrm{MSH}$ is only about $5 \%$ of that of the pituitary. ${ }^{6}$

The chemical nature of immunoreactive $\beta-\mathrm{MSH}$ in CSF is unknown, but it is believed that in the pituitary and plasma $\beta-\mathrm{MSH}$ occurs only as part of the larger lipotrophin (LPH) molecule ${ }^{8}$ which cross-reacts in our assay. ${ }^{9}$ The $C$ terminus (61-91) of $\beta$-LPH has been shown to have a high affinity for brain opiate receptors and thus an important physiological role in the nervous system ${ }^{1011}$; in addition, the portion of the molecule common to the MSHs (51-58) also influences central nervous activity. ${ }^{12-16}$ Our study suggests that $\mathrm{MSH}$ peptides are produced by the central nervous system as well as acting on it.

We are grateful to the Medical Research Council (SS \& AJT) and the Wellcome Trust (AS).

\section{References}

1 Smith, A G, and Shuster, S, Lancet, 1976, 1, 1321.

2 Jordan, R M, et al, Annals of Internal Medicine, 1976, 85, 49.

3 Thody, A J, and Plummer, N A, Fournal of Endocrinology, 1973, 58, 263.

4 Hall, R, et al, Fundamentals of Clinical Endocrinology, p 25. London, Pitman Medical, 1974.

${ }^{5}$ Holdaway, I M, Rees, L H, and Landon, J, Lancet, 1973, 2, 1170.

6 Carter, R J, et al, unpublished observations.

7 Pearse, A G E, Nature, 1976, 262, 92.

${ }^{8}$ Bloomfield, G A, et al, Nature, 1974, 252, 492

- Gilkes, J J H, et al, Fournal of Clinical Endocrinology and Metabolism, $1975,40,450$.

10 Bradbury, A F, et al, Nature, 1976, 260, 793.

11 Guillemin, R, New England fournal of Medicine, 1977, 296, 226.

12 Sandman, C A, Kastin, A J, and Schally, A V, Physiology Behaviour, $1971,6,45$.

${ }^{13}$ Krivoy, W A, and Guillemin, R, Endocrinology, 1961, 69, 170.

${ }^{14}$ DeWied, D, Witter, A, and Greven, H M, Biochemical Pharmacology, $1975,24,1463$

15 Leonard, B E, et al, fournal of Neuroscience Research, 1976, 2, 39.

16 Rigter, H, Shuster, S, and Thody, A J, Fournal of Pharmacy and Pharmacology, 1977, 29, 110.

(Accepted 22 April 1977)

\section{SIDE EFFECTS OF DRUGS}

\section{Proximal myopathy after perhexiline maleate treatment}

Perhexiline maleate (Pexid) has proved effective in treating angina pectoris, and adverse reactions to the drug have been minor. ${ }^{12} \mathrm{We}$ report here a case of proximal myopathy that occurred after perhexiline treatment.

\section{Case report}

A 67-year-old woman presented in October 1976 with an 18-month history of ischaemic chest pain provoked by exertion. Two weeks before presentation the pain had become more frequent and more prolonged and associated with shortness of breath. There were no other relevant features or medical history. Physical and electrocardiographic examination showed nothing abnormal. Angina pectoris was diagnosed, and treatment with perhexiline maleate $200 \mathrm{mg}$ twice daily was started.

Two weeks after starting treatment the patient developed unsteadiness and weakness in her legs. After three weeks' treatment she developed an itching, burning generalised rash, so the drug was stopped. On admission to hospital 10 days later she had a fading generalised scarlatiniform rash with erythema and desquamation, particularly of the palms and back but also of the buccal mucosa, scalp, and body. The muscles of both shoulders and hips were very weak, and she could not rise unaided from a squatting position. There was no muscle wasting; cranial nerves, tendon reflexes, and sensation were normal; and plantar reflexes were flexor. No other abnormality was found. It was considered that her skin lesions and proximal myopathy were due to perhexiline.
Further investigations included a full blood count; urine analysis; chest radiograph; electrocardiogram; and blood urea, blood sugar, and electrolyte estimation-all of which were normal. Serum calcium, serum creatinine phosphokinase, liver function, plasma cortisol, and serum thyroxine were also normal. The erythrocyte sedimentation rate was $37 \mathrm{~mm}$ in the first hour. Antinuclear factor was positive to a titre of $1 / 64$, but LE cells were absent.

Nerve conduction velocity was normal at $48 \mathrm{~m} / \mathrm{s}$ (lateral popliteal nerve). Electromyography of quadriceps femoris showed no insertional activity and no fasciculation at rest. Maximal contraction produced a moderately full interference pattern of low amplitude motor potentials of high frequency, which was compatible with a diagnosis of myopathy.

The rash settled within three weeks of stopping the perhexiline and the myopathy resolved within two months.

\section{Comment}

Perhexiline maleate is an effective treatment for angina pectoris, but unwanted side effects are common though not usually serious. ${ }^{12}$ Adverse reactions occur mainly within the first month of treatment and are readily reversed by stopping the drug. ${ }^{2}$ Abnormalities of liver function tests and peripheral neuropathy tend to occur later in the course of treatment but are still reversible. ${ }^{34}$

Proximal myopathy is a well-recognised feature of several endocrine and metabolic disorders and occurs as a side effect of many drugs. In our patient there can be no doubt of the diagnosis, since she had both the clinical and electromyographic features of proximal myopathy . Because she had no evidence of any metabolic or endocrine disorder and had taken no drug other than perhexiline, it seems probable that perhexiline was the cause of her myopathy.

In drawing attention to this uncommon side effect of perhexiline 